\title{
Environmental considerations on solar disinfection of wastewater and the subsequent bacterial (re)growth
}

\author{
Stefanos Giannakis*,1,2,3, Efthymios Darakas ${ }^{1}$, Antoni Escalas-Cañellas ${ }^{2,4}$, César Pulgarin ${ }^{3, *}$ \\ ${ }^{1}$ Laboratory of Environmental Engineering and Planning, Department of Civil Engineering, Aristotle University of Thessaloniki, \\ 54124 Thessaloniki, Greece \\ ${ }^{2}$ Laboratory of Control of Environmental Contamination, Institute of Textile Research and Industrial Cooperation of Terrassa \\ (INTEXTER), Universitat Politècnica de Catalunya, Colom 15, 08222 Terrassa, Catalonia, Spain \\ ${ }^{3}$ Swiss Federal Institute of Technology, Lausanne, Institute of Chemical Sciences and Engineering, 1015 Lausanne, Switzerland \\ ${ }^{4}$ Department of Chemical Engineering \& Terrassa School of Engineering, Universitat Politècnica de Catalunya, Colom 1, 08222, \\ Terrassa, Catalonia, Spain
}

*Corresponding author: Stefanos Giannakis, Tel: +41216935261 ;

E-mail: stefanos.giannakis@epfl.ch

*Corresponding author: César Pulgarin, Tel: +41216934720;

E-mail: cesar.pulgarin@epfl.ch

\begin{abstract}
In this work, solar disinfection of wastewater was studied, focused on the effect of selected environmental variables, namely, light intensity, continuous/intermittent light delivery, and post-irradiation storage as well as dilution in lake water. These variables were studied for their effect on disinfection efficiency and on post-irradiation survival/regrowth in undiluted wastewater and in wastewater diluted in lake water at different dilution rates. The bacterial inactivation curves were studied, and distinct kinetic phases were identified and interpreted. Dose primarily influenced the phases' demonstration and total inactivation times, independently from the irradiance. Intermittent illumination un-evenly prolonged the required exposure time and pointed to extended longer required illumination times when unstable weather conditions are to be expected. Post-irradiation survival/regrowth in undiluted wastewater showed three distinct kinetic profiles, with the transitions among them largely determined by the inflicted light dose. Lower doses resulted in similar inactivation profiles as high ones, when irradiation was followed by prolonged storage at high dilution rates in lake water. The studied factors show significant design and operation implications for solar wastewater applications, based on local environmental conditions and water receptor restrictions.
\end{abstract}

Keywords: environmental influence, solar disinfection, wastewater, E. coli, regrowth 


\section{Introduction}

Solar light has demonstrated disinfecting capabilities, due to the action mode of UVB and UVA wavelengths (Bosshard et al., 2010; Douki, 2013). For drinking water, it has been greatly used as a practice in developing countries (McGuigan et al., 2012) and the application in form of ponds for wastewater treatment has also been investigated in tropical latitude (von Sperling, 2005). The aforementioned regions coincide with the higher number of sunny days per year and therefore are ideal candidates for such practices.

The efforts to implement field application of solar wastewater have been reported in works in tropical regions in Africa (Maïga et al., 2009), Oceania (Davies-Colley et al., 2003), Asia (Khosravi et al., 2013) and more, with success in terms of removal rates for bacteria, viruses and other microorganisms. Von Sperling et al., (2005) have reviewed the data of 186 facultative and maturation ponds around the world and in terms of geographical distribution, the majority of these data were extracted from applications in Brazil and tropical regions.

Typically these applications are in the form of: primary facultative ponds, secondary facultative and maturation ponds (von Sperling, 2005). In another work, the use of lagoons was studied, with decreasing efficiency in the inactivation efficiency, as the series evolve (Xu et al., 2002). Finally the use of waste stabilization ponds for the reduction of effluent pollution was implemented (Bolton et al., 2010) and the ecologically engineered high rate ponds with mixing (Craggs et al., 2004) are some of the forms in which

solar wastewater disinfection was implemented. In most of the cases the limits of discharge for irrigation were achieved, but it requires long exposure times which discourage the application.

One of the most decisive factors of solar disinfection is the availability of light (Fabriccino and d'Antonio, 2011). In most cases, areas with challenged water supplies are subjected to many sunny days per year (Blesa and Litter, 2007), but for instance, solar-UV power is a function of sky clarity and of the presence of clouds. The solar-only disinfection is affected by changes in irradiation intensity, and therefore, takes place (more efficiently) at higher irradiance values (Sichel et al., 2007). However, even in the sunniest areas in the world, the UV supply can be subjected to temporal variations; therefore, it is important to assess the implications light intermittence would cause to the removal efficiency of a solar wastewater application.

Furthermore, unlike the chemical methods for disinfecting wastewater, solar exposure lacks residual activity, and when the illumination is over, there is no disinfecting action (White, 2010). Many 
microorganisms (e.g. bacteria, viruses) have demonstrated a capability to repair the damages through several mechanisms, after the end of the exposure to UV (Quek and Hu, 2008). In addition, wastewater is an abundant source of nutrients for microorganisms, and apart from the normal, expected growth, regrowth is also bound to manifest (Oguma et al., 2002) and has to be considered as a primary problem (Blatchley et al., 2007). Regrowth of bacteria in the natural environment through the aforementioned pathways, depending on the receiving water body, could result in re-contamination of downstream water supplies or coastal areas (Yamahara et al., 2007).

However, according to the type of receiving water body and conditions during discharge, there is different response expected. In natural aquatic environments carbon availability and temperatures are much lower and therefore, the expected specific growth rates of enteric bacteria are lower (Berney et al., 2007). The occurrence of microorganisms in natural waters has been a subject of study in receptors such as rivers (Avery et al., 2008), lakes (Haller et al., 2009), estuarine waters (Chandran and Hatha, 2005; Kay et al., 2005), brackish water (Boukef et al., 2010) and seawater (Noble et al., 2004; Darakas et al., 2009), which indicate the aforementioned differentiated response.

The main goal of this work is to study environmental factors which pose a challenge in the success of solar-oriented applications of wastewater disinfection, such as the effects of irradiation intensity, the delivery method of the light (continuous-intermittent) and the fate of microorganisms after their exit from the disinfecting unit and their introduction to natural waters. Therefore, the objective of this work is to explore the bacterial activity while water is acquiring the necessary dose for inactivation. For this purpose:

a. Solar light intensity was changed to reflect some of the intensities occurring during exposure.

b. Different exposure and dark sequences were used to test bacterial response, when irradiation is intermittent, either after short or long dark periods.

c. Pre-illuminated bacteria were introduced in lake water at different wastewater/lake water ratios, to simulate i) the response after various damage levels inflicted by solar light and ii) the survival/regrowth potential of the damaged bacteria for 5 days, as a function of the nutrient availability. 


\section{Materials and methods}

\subsection{Bacterial strain preparation}

An E. coli K12 strain was used in all experiments, provided by DSMZ (Deutsche Sammlung von Mikroorganismen und Zellkulturen GmbH (DSMZ), Braunschweig, Germany (ATCC23716). Luria Bertani (LB) broth was prepared for each experimental series by adding $10 \mathrm{~g}$ Tryptone, $5 \mathrm{~g}$ yeast extract and $5 \mathrm{~g} \mathrm{NaCl}$ in Mili-Q water and autoclaving for heat-sterilization. A colony from pre-cultures was inoculated in $5 \mathrm{~mL}$ of sterile LB in a sterile plastic falcon, followed by 8 -h incubation and rotation at $37^{\circ} \mathrm{C}, 1 \%$ further dilution in $250 \mathrm{~mL}$ LB broth and 15 hours further incubation.

The stationary cells were collected by centrifugal separation from the broth $\left(15 \mathrm{~min}\right.$ at $500 \times \mathrm{g}$ and $\left.4{ }^{\circ} \mathrm{C}\right)$, followed by 3 rounds of washing by sterile saline solution $(\mathrm{NaCl}: 8 \mathrm{~g} / \mathrm{L}, \mathrm{KCl}: 0.8 \mathrm{~g} / \mathrm{L}, \mathrm{pH}: 7-7.5)$. The final pellet was again suspended in sterile saline solution, forming a bacterial solution of approximately $10^{9}$ colony forming units per milliliter $(\mathrm{CFU} / \mathrm{mL})$. This solution was used to form the initial $10^{6}$ population in all experiments, by diluting $1 \mathrm{~mL}$ in $1 \mathrm{~L}$ of synthetic wastewater.

\subsection{Synthetic wastewater composition and preparation}

The composition of the wastewater was obtained from OECD (OECD, 2001): $160 \mathrm{mg} / \mathrm{L}$ peptone, 110 $\mathrm{mg} / \mathrm{L}$ meat extract, $30 \mathrm{mg} / \mathrm{L}$ urea, $28 \mathrm{mg} / \mathrm{L} \mathrm{K}_{2} \mathrm{HPO}_{4}, 7 \mathrm{mg} / \mathrm{L} \mathrm{NaCl}, 4 \mathrm{mg} / \mathrm{L} \mathrm{CaCl} \cdot 2 \mathrm{H}_{2} \mathrm{O}$ and $2 \mathrm{mg} / \mathrm{L}$ $\mathrm{MgSO}_{4} \cdot 7 \mathrm{H}_{2} \mathrm{O}$. A further $10 \%$ dilution was applied to the final solution to better simulate the organics content of secondary treated wastewater. The solution was then heat sterilized and used fresh in all experiments.

\subsection{Suntest solar simulator specifications}

The light source used in all experiments was a CPS Suntest solar simulator (Atlas GmbH). The apparatus bears a $150-\mathrm{W}$ air-cooled Xenon lamp, with $560 \mathrm{~cm}^{2}$ illuminated surface. $0.5 \%$ of the light is emitted in the UVB region, $5 \%$ in the UVA and the rest (above $400 \mathrm{~nm}$ ) follows the solar spectrum. Cut-off filters blocked the emission of UVC and infrared wavelengths. The intensities used are: 500, 600, 1000 and $1200 \mathrm{~W} / \mathrm{m}^{2}$ for the inactivation tests, $1200 \mathrm{~W} / \mathrm{m}^{2}$ for the intermittence test and $1000 \mathrm{~W} / \mathrm{m}^{2}$ for the study of subsequent survival in lake water. 500 and $600 \mathrm{~W} / \mathrm{m}^{2}$ correspond to a relative minimum in SODIS tests, while $1000 \mathrm{~W} / \mathrm{m}^{2}$ is a desired (and achievable) intensity in the candidate countries for solar wastewater disinfection. Although $1200 \mathrm{~W} / \mathrm{m}^{2}$ is an elevated value, its use facilitates a ground for comparison in the 
intermittence test. Previous assays (data not shown) have demonstrated less profound effects at 1000 $\mathrm{W} / \mathrm{m}^{2}$, hence $1200 \mathrm{~W} / \mathrm{m}^{2}$ was chosen to represent the phenomenon.

\subsection{Microbial enumeration}

Plate count agar (PCA) was used as a growth medium for the enumeration of colony forming units, pourplated on sterile, 9-cm plastic Petri dishes. The optimal count range is $15-150$ colonies per plate; here, the actual number of CFU is reported in all cases. The limits of detection for undiluted samples is $1 \mathrm{CFU} / \mathrm{mL}$ and for diluted samples is $10 \mathrm{CFU} / \mathrm{mL}$.

\subsection{Post-irradiation measurements}

Bacterial survival/regrowth was monitored by daily measurements from the samples drawn during the experiments. $1 \mathrm{~mL}$ samples were kept in dark conditions at room temperature, in sterile plastic Eppendorf caps. For the survival experiments in lake water, samples were diluted $(10 \%$ and $1 \%)$ in sterile dark bottles containing the lake water. Regrowth testing took place from water drawn from the diluted samples.

\subsection{Experimental details}

For all the experiments, $50-\mathrm{mL}$ samples were exposed to simulated solar light, contained in glass reactors, of $65 \mathrm{~mL}$ total volume. The specific dimensions were: $3.8 \mathrm{~cm}$ diameter, $9 \mathrm{~cm}$ height, with cap neck included, $70.6 \mathrm{~cm}^{2}$ effective irradiation surface. Magnetic bars in the reactors ensured mild stirring throughout the experimental times.

The intermittence test took place at $1200 \mathrm{~W} / \mathrm{m}^{2}$. During the 6 hours of experimental time, considering the first and last hour as illuminated times (or else the total time is $5 \mathrm{~h}$ ), there are 14 combinations of 1, 2 or 3 hour light intermittence, which were simulated in the assay. The different combinations are presented in Figure 2a.

The post-irradiation events after the varied intensities test were monitored for a subsequent 48-h period, whereas the survival experiments in lake water were monitored for a 5-day period after the completion of irradiation. Finally, lake water was heat-sterilized prior to use, to eliminate the possible action of indigenous microorganisms naturally present, and focus exclusively on the physicochemical effects of the recipient. 


\section{Results and Discussion}

\subsection{Irradiance effects on solar wastewater disinfection}

First of all, in the low intensities (500 and $600 \mathrm{~W} / \mathrm{m}^{2}$ ) presented in Figure 1, the initial impact of light has a detrimental effect on bacterial survival, mainly initiated by the acute change in conditions (dark to light). Both curves present rapid decrease of the bacterial concentration (around 55\% decrease). However, this period is followed by a period of recovery of the population. Although the inactivation rates were quite similar, the re-population of the sample followed the trend of the applied intensity; higher photonic rate resulted in profound and rapid recovery.

A possible explanation could be attributed to the response to the UV damage inflicted to the cell, where elevated irradiance could provide a higher bacterial response, to recover the DNA lesions and therefore, higher recovery and cultivable cells. This elevated population would result to higher reproduction effects. Normally, during illumination experiments, bacteria that are not critically wounded maintain their cultivability. Finally, according to Rincon and Pulgarin (2007), photo-activation of dormant cells was observed when the samples were irradiated; considering the lag in the demonstration of this early recovery, this could provide an explanation, also justifying the trend of increasing recovery with increasing irradiance.

Furthermore, after the recovery phase, a permanent declining trend with a tail is observed, until total inactivation is achieved. From the time recovery started, there are two separate periods where inactivation is observed, an acute and a significantly milder one. The two phases are justified by the inactivation profile known in solar disinfection, which dictates generation of photoproducts (Rincon and Pulgarin, 2004) and gradual disruption of the respiratory cycle of the cells (Bosshard et al., 2010); these effects are cumulative and their result is bacterial inactivation. However, the tailing effect is attributed to i) the new generations of the cells which have developed photo-resistance (Quek and Hu, 2008) and the ones that have escaped illumination due to shielding, aggregation etc. (Craik et al., 2001). The latter ones maintain their cultivability, thus continue to replicate and delay total inactivation for 120 and 90 min, for 500 and $600 \mathrm{~W} / \mathrm{m}^{2}$, respectively.

For the higher intensities, the inactivation profile presents a small initial delay, followed by a long period of acute inactivation and a significantly shorter tail. For the first 30-60 min, the inactivation rate is lower, and is a common finding (Berney et al., 2006; Ndounla et al., 2014) among photo-inactivation assays. There exists a concomitant growth of the population alongside with the inactivation caused by UVA and 
UVB. The equilibrium among the two actions is always in favor of inactivation, but it is only after the second hour that the inactivation profile represents a monotonous reduction. Total inactivation $\left(6-\log _{10} \mathrm{U}\right)$ is achieved in 210 and $160 \mathrm{~min}$, for 1000 and $1200 \mathrm{~W} / \mathrm{m}^{2}$, respectively. The higher irradiance is explaining the difference in the curves; Harm (1980) presented the theory where a significant number of targets need to be hit in order to inactivate bacteria. Bosshard et al., (2010) and Berney et al., (2006) identified the targets. A higher flux can statistically achieve higher number of effective hits in the vital functions of the cell and result to faster loss of cultivability. Conversely, lower flux caused a longer tail effect on the kinetic curves due to higher adaptation rates. It is also evident that the two opposing forces of growth and disinfection are in a relative equilibrium for longer periods of time in the lower intensities rather than the high ones. The shoulder disappearance corresponds to the manifestation of the high intensity effects.

In terms of dose, there is a very interesting finding that correlates inactivation and irradiance. The delay before the acute inactivation phase in low intensities was achieved in very similar doses. For $500 \mathrm{~W} / \mathrm{m}^{2}$, the rapid phase was observed after $210 \mathrm{~min}$, while at $600 \mathrm{~W} / \mathrm{m}^{2}$ it was observed around $150 \mathrm{~min}$. This means that the end of the shoulder period appeared at around $1650 \mathrm{Wh} / \mathrm{m}^{2}$, for both curves. Similarly, the dose that ensured inactivation in high doses was also of close value. According to the definition of solar dose, we get:

$$
D=I x t
$$

Where:

D: is the inflicted dose $\left(\mathrm{Wh} / \mathrm{m}^{2}\right)$,

I: is the intensity of light and $\left(\mathrm{W} / \mathrm{m}^{2}\right)$

$\mathrm{t}$ : is the exposure time (s).

In this classic approach of dose calculations, the dose required to initiate permanent inactivation is very close between the two cases in low intensity light. For the high intensities, a similar effect is observed in the inactivation phase, considering that the shoulder-lag phase is relatively short. The dose required until the tailing period is very similar. The required dose to achieve 4- $\log _{10} \mathrm{U}(99.99 \%)$ reduction of bacteria is $3000,2950,3100$ and $3060 \mathrm{Wh} / \mathrm{m}^{2}$, for $500,600,1000$ and $1200 \mathrm{~W} / \mathrm{m}^{2}$ intensity. However, trying to extend this observation in the tailing period, the error margin is bigger, in both high and low intensities.

In overall, the necessary dose to completely inactivate bacteria, regardless of the employed intensity level, is very close in all cases. These findings contradict the existing literature in drinking water, where the same dose had better effects at higher intensities (Ubomba-Jaswa et al., 2009; Ndounla et al., 2014). The 
most probable cause for these results, is the discontinuous manner of delivery of light in field applications. Here, the source is i) constant and continuous without intermittence and ii) in relatively close intensities; the comparison in this cases is valid and effective.

\subsection{Events during light intermittence}

In this experimental sequence, the effect of naturally interrupted delivery of light -like temporal cloudiness-was simulated. In 6 hours, the possible combinations of 1, 2 or 3 hours of intermittent irradiation are shown in Figure 2a, as well as the normalized results. The first and last hour are always illuminated, and the periods in between represent14 possible scenarios of intermittent irradiation. In Figure $2 \mathrm{~b}$ the scenarios are grouped by line color, where $(-)$ are the scenarios that end after 3 hours in total, (-) are the scenarios that end after 4, (-) are the scenarios that end after 5 and (-) the ones scenarios that end after 6 hours of experimentation. The traces show the ones in which 1 hour of stoppage was inserted $(\bullet),(\bullet)$ for 2 hours and $(\boldsymbol{+})$ for 3 hours total light interruption.

As observed from Figure $2 \mathrm{~b}$, all inactivation curves presented an initial shoulder phase, followed by a sharp decay phase, similarly to the continuous illumination experiments, and as it is found in the literature (Berney et al., 2006; Misstear et al., 2013). Regarding the time required for total inactivation, 2 scenarios reached total inactivation in 3 hours, both receiving 3 initial hours of continuous illumination, which corroborates the findings presented in the previous sub-section. Inserting 1 to 3 hours of darkness extended either the shoulder or the decay phases, lengthening the total disinfection time to $4 \mathrm{~h}$ (four scenarios), $5 \mathrm{~h}$ (four scenarios) or $6 \mathrm{~h}$ (the other four scenarios).

At this point it is interesting to estimate the effect of light interruption on the total disinfection time. Scenarios 1-4 are interrupted for one hour .So, normally, the delay should be maximum one hour, increasing the total in $4 \mathrm{~h}$ of experimentation. However, Scenario 1 is completed after 5 hours, presenting a total delay of $2 \mathrm{~h}$. Hence, it is observed that in this case, the intermittence took place as early as possible, and delayed the process significantly. It is then made clear that the important time of continuous exposure is during the first 2 hours, for this intensity, or else the process is unevenly prolonged. In the same prism, the 2-h intermittence experiments are expected to be completed in $5 \mathrm{~h}$, but there are some scenarios that are completed in $4 \mathrm{~h}$. In this case, there has been at least $2 \mathrm{~h}$ of initial continuous illumination, and the accumulated damage is enough to disrupt the normal growth profile and even more, initiate inactivation in the dark. Finally, the 3-h intermittence scenarios are expected to finish in $6 \mathrm{~h}$, and it is verified; it seems that there is an effective dose, achieved in all the exposure time, at this intensity, which ensures total inactivation within the 6 hours of experimentation. 
In overall, the results of different illumination conditions after the first hour of light exposure, confirmed the importance of continuous, constant irradiation during the initial 2-h period. When these conditions existed, a 1-h shoulder was normally demonstrated. Upon the infliction of intermittence in light supply, a shoulder up to 3-h was observed. In a potential application of solar wastewater disinfection, the temporal weather changes need to be taken into account, to better simulate the necessary exposure times. In the studied cases, $6 \mathrm{~h}$ were sufficient to cause inactivation, even with $3 \mathrm{~h}$ of dark periods. However, in real applications, where lower intensities are expected, higher or much higher exposure times should be accounted for in the dimensioning of the system.

\subsection{Implications in post-irradiation kinetics of photo-damaged E. coli}

\subsubsection{Survival kinetics in solar treated wastewater}

Figures $3 \mathrm{a}$ and $3 \mathrm{~b}$ present the results of the post-experimental monitoring of simulated solar light on wastewater samples. In figure $3 \mathrm{a}$, the survival/regrowth kinetics of the low intensity experiments are shown, separating the results from 500 and $600-\mathrm{W} / \mathrm{m}^{2}$ inflicted irradiance. The two profiles visible after 48 hours are a decay and a recovery of the population.

Different characteristic kinetic profiles are observed in the survival/regrowth curves, namely: a) outright regrowth, b) decay, then regrowth, c) monotonous decay, usually slower during the second day. Outright regrowth appears only after a short irradiation time and low dose at $600 \mathrm{~W} / \mathrm{m}^{2}$. A range of higher irradiation times and/or intensities provide a decay-then-regrowth profile. Finally, the highest intensities and/or exposure times result in monotonous decay. For instance, at $500 \mathrm{~W} / \mathrm{m}^{2}, 2$ hours under simulated solar light cause an initial decay, followed by growth, while under $600 \mathrm{~W} / \mathrm{m}^{2}$ the profile reveals monotonous decay. The same applies for a 3-h exposure, where decay is moderate after $48 \mathrm{~h}$ at $500 \mathrm{~W} / \mathrm{m}^{2}$ and intense, even in $24 \mathrm{~h}$ at $600 \mathrm{~W} / \mathrm{m}^{2}$.

Furthermore, separating the findings per applied irradiance, there are distinct profiles, according to the exposure time. At $500 \mathrm{~W} / \mathrm{m}^{2}$, after $2 \mathrm{~h}$ illumination, bacteria can recover the solar-inflicted damage, after $3 \mathrm{~h}$ the results present moderate decay and after $3 \mathrm{~h}$, permanent decay behavior. However, at $600 \mathrm{~W} / \mathrm{m}^{2}$, the same findings are verified, but one hour earlier than the case of $500 \mathrm{~W} / \mathrm{m}^{2}$. This indicates a dose relationship, as seen also in disinfection, and implying an energy threshold beyond which inactivation is permanent and rather bound to happen even in long term. 
In Figure 3b, due to the difference in time intervals, the comparison between 60 min-irradiaton kinetics is of great interest. In this case, 1000 and $1200 \mathrm{~W} / \mathrm{m}^{2}$ present modified response after $1 \mathrm{~h}$; although a decay phase has already began, at $1000 \mathrm{~W} / \mathrm{m}^{2}$ in $48 \mathrm{~h}$ a minor recovery is observed, contrasting the higher residual bacterial number, but consistent decay presented in $1200 \mathrm{~W} / \mathrm{m}^{2}$ curves. In the case of $1000 \mathrm{~W} / \mathrm{m}^{2}$, the change in kinetics from growth to decay profile is taking place between 60 and 90 min of irradiation, while at $1200 \mathrm{~W} / \mathrm{m}^{2}$, this modification takes place between 40 and $60 \mathrm{~min}$. Hence, in all cases presented so far, the increase in light intensity has moved this "breaking point" in bacterial kinetics earlier in time, indicating the differentiated response of bacteria against solar light dose. Therefore, apart from the necessary dose to inflict total inactivation, we suggest that another point exists, at which bacteria are deterministically decaying in long term storage. The calculated dose for achieving long term inactivation is around $1250 \mathrm{Wh} / \mathrm{m}^{2}$, regardless of the intensity used. In this case, even in the presence of nutrients and dark conditions, bacteria were not able to perform dark repair.

\subsubsection{Survival kinetics in lake water}

In the previous regrowth tests, the bacterial kinetics in wastewater were studied after solar exposure and a subsequent 48 -h dark period. Nutrients were present at considerable concentration in those regrowth experiments, but this is not always the case in nature. In this assay, lake water was used as the receiving medium of solar-treated wastewater. Also, as in some cases the kinetics presented a plateau, the monitoring period was extended to 5 days, for a better view of the survival capabilities.

Figure 4 presents the bacterial survival after simulated solar disinfection at $1000 \mathrm{~W} / \mathrm{m}^{2}$, chosen as a normal value to encounter in candidate countries for application. Along with the irradiated tests, the behavior of untreated bacteria is presented for reference. As it is shown, untreated bacteria went through a growth period, lasting 3 days, and then presented a tendency to stabilize their population. The dilution rate between wastewater and lake water affected the nutrient availability. However, starting from a lower initial concentration, bacteria suspended in $1 \%$ dilution presented faster growth kinetics, due to the minimization of the competition for nutrients per cell. The dilution in lake water is osmotically neutral for untreated bacteria, as the effect of growth is visible in both cases, and bacteria can maintain their life cycle; there are reports of the presence of bacteria for weeks (Darakas, 2001) even months in lake sediments (Haller et al., 2009). 
When an hour of illumination preceded the dilution in lake water the kinetics were differentiated. Both cases presented a small growth period $(24 \mathrm{~h})$, which continued only for the $10 \%$ diluted samples. On the contrary, in $1 \%$ diluted samples a slight decay period was initiated. This behavior can be attributed to the nutrients availability of $10 \%$ diluted sample over $1 \%$, but considering the behavior of the untreated sample, it is given to understand that either the $10 \%$ sample is statistically favored to contain more healthy cells and therefore, reproduction, or the positive influence of the wastewater matrix is lost, over the dilution in lake water.

Also, what is interesting, is the comparison of the growth rates between lightly treated and untreated cells. Especially in $10 \%$, higher growth rates were observed, in the first 3 days, which indicated a response: bacteria that were damaged and/or not lethally wounded, when the damage was repaired, they acquired additional resistance to the osmotic difference. This response was first stated by Trousselier et al. (1998), who attributed higher resistance in a shock, if it is preceded by another stress. The RpoS gene is responsible for initiating anti-stress response (Vidovic et al., 2012), it seems it could also be the case here. Finally, after 2 hours of illumination, the accumulation of damage makes repair impossible. The kinetics reveals a continuous decay phase. However, the dilution rate, i.e. higher nutrient content in $10 \%$ and more favorable conditions delay the process for another $24 \mathrm{~h}$, compared to $1 \%$ kinetics.

Considering the necessary time to completely inactivate bacteria, in the previous section it was found to be around 160 minutes. What is observed here is that dilution in natural water at high rate, could impose bacterial inactivation with less irradiation time, in long term storage. For example, bacteria treated for 120 min, diluted at $1 \%$ rate were completely inactivated in 4 days. If the exposure time is increased, as well as the dilution, it is implied that the necessary times for long-term "self-inactivation" could be relatively shorter. Hence, the disposal of solar treated wastewater and the retention times in the application can be greatly influenced by the following conditions. In plain storage the required times were higher, due to nutrient abundance, but in natural water, even in osmotically neutral, the decay was higher. 


\section{Conclusions}

The kinetics of simulated solar disinfection of wastewater consistently showed distinct phases. An initial delay period (shoulder lag phase) was always visible, with decreasing lengths as solar irradiance was increased, followed by a monotonous inactivation period, and closing with a slower, tailing phase. In parallel, elimination of the fluctuations in the bacterial population during the lag phase was observed, linked to the effectiveness of higher irradiance. Furthermore, the dose required for total inactivation was almost constant in these conditions.

When the manner of light delivery at high intensities was intermittent, important differences in the inactivation kinetics were found; intermittence un-evenly prolonged the irradiation times, with its delaying action being more effective in the first hours of the exposure time. The delays in total disinfection provoked by the dark periods were significantly longer than the dark periods themselves when the breaks in illumination took place early in the exposure, thus extending the experimental time required for total disinfection. The deterministic decay observed late in the inactivation kinetics indicates the mild effect intermittence has, towards the end of the exposure times.

Regarding regrowth in wastewater, dose is dictating the survival kinetics in the dark. At increasing intensities, an inverse proportional change in time was observed to inflict a similar kinetics profile, indicating its correlation with the dose. Also, higher intensity resulted in sharp bacterial decay in the dark, which was also the main long-term inactivation force. In lake water, higher doses resulted in faster selfdecay response on the dark, in contrary to the non-irradiated samples that, after a shock phase, presented growth. Dilution was an equally decisive parameter, defining the final nutrient availability and therefore affecting the long term capability of bacterial survival.

Conclusively, considering an application destined for solar wastewater disinfection, apart from the endogenous factors, there are exogenous ones influencing the outcome of the process. The success of this application lies i) primarily in light availability and intensity, ii) in the prediction for potential prolonged exposure if temporal clouding is expected frequently, and iii) the receiving water medium. As it seems, tuning the design of a solar disinfection unit as a whole, it can reduce the exposure times and therefore, result in smaller and more efficient facilities. All things considered, a locally oriented approach is necessary for proper design of solar disinfection applications, and most importantly, a holistic vision of the involved parts from the introduction of wastewater to the system, until its release. 


\section{Acknowledgments}

Stefanos Giannakis acknowledges the Swiss Agency for Development and Cooperation (SDC) and the Swiss National Foundation for the Research for Development Grant, for the funding through the project "Treatment of the hospital wastewaters in Côte d'Ivoire and in Colombia by advanced oxidation processes" (Project No. 146919).

\section{References}

Avery, L. M., Williams, A. P., Killham, K., \& Jones, D. L. (2008). Survival of Escherichia coli O157:H7 in waters from lakes, rivers, puddles and animal-drinking troughs. Sci Total Environ, 389(2-3), 378-385. doi: 10.1016/j.scitotenv.2007.08.049

Berney, M., Weilenmann, H. U., Simonetti, A., \& Egli, T. (2006). Efficacy of solar disinfection of Escherichia coli, Shigella flexneri, Salmonella Typhimurium and Vibrio cholerae. J Appl Microbiol, 101(4), 828-836. doi: 10.1111/j.1365-2672.2006.02983.x

Berney, M., Weilenmann, H.-U., \& Egli, T. (2007). Adaptation to UVA radiation of E. coli growing in continuous culture. Journal of Photochemistry and Photobiology B: Biology, 86(2), 149-159.

Blatchley, E. R., Gong, W.-L., Alleman, J. E., Rose, J. B., Huffman, D. E., Otaki, M., \& Lisle, J. T. (2007). Effects of wastewater disinfection on waterborne bacteria and viruses. Water environment research, 79(1), 81-92.

Blesa, M. A., \& Litter, M. I. (2007). Low-cost $\mathrm{TiO}_{2}$ photocatalytic technology for water potabilization in plastic bottles for isolated regions. Photocatalyst fixation.

Bolton, N. F., Cromar, N. J., Hallsworth, P., \& Fallowfield, H. J. (2010). A review of the factors affecting sunlight inactivation of micro-organisms in waste stabilisation ponds: Preliminary results for enterococci. Vol. 61. Water Science and Technology (pp. 885-890).

Bosshard, F., Bucheli, M., Meur, Y., \& Egli, T. (2010). The respiratory chain is the cell's Achilles' heel during UVA inactivation in Escherichia coli. Microbiology, 156(7), 2006-2015.

Boukef, I., El Bour, M., Al Gallas, N., El Bahri, O., Mejri, S., Mraouna, R., . . Troussellier, M. (2010). Survival of Escherichia coli strains in mediterranean brackish water in the Bizerte lagoon in Northern Tunisia. Water environment research, 82(11), 2249-2257.

Chandran, A., \& Mohamed Hatha, A. A. (2005). Relative survival of Escherichia coli and Salmonella typhimurium in a tropical estuary. Water Res, 39(7), 1397-1403. doi: 10.1016/j.watres.2005.01.010

Craggs, R. J., Zwart, A., Nagels, J. W., \& Davies-Colley, R. J. (2004). Modelling sunlight disinfection in a high rate pond. Ecological Engineering, 22(2), 113-122. doi: 10.1016/j.ecoleng.2004.03.001

Craik, S. A., Weldon, D., Finch, G. R., Bolton, J. R., \& Belosevic, M. (2001). Inactivation of Cryptosporidium parvum oocysts using medium-and low-pressure ultraviolet radiation. Water Res, 35(6), 1387-1398.

Darakas, E. (2001). A simple mathematical formula describing the survival kinetics of E. coli in natural waters. International Journal of Environmental Studies, 58(3), 365-372.

Darakas, E., Koumoulidou, T., \& Lazaridou, D. (2009). Fecal indicator bacteria declines via a dilution of wastewater in seawater. Desalination, 248(1-3), 1008-1015. doi: 10.1016/j.desal.2008.10.017

Davies-Colley, R. J., Craggs, R. J., \& Nagels, J. W. (2003). Disinfection in a pilot-scale "advanced" pond system (APS) for domestic sewage treatment in New Zealand. Water Sci Technol, 48(2), 81-87. 
Douki, T. (2013). The variety of UV-induced pyrimidine dimeric photoproducts in DNA as shown by chromatographic quantification methods. Photochemical \& Photobiological Sciences, 12(8), 1286-1302.

Fabbricino, M., \& d'Antonio, L. (2012). Use of solar radiation for continuous water disinfection in isolated areas. Environmental Technology, 33(5), 539-544. doi: 10.1080/09593330.2011.584570

Haller, L., Amedegnato, E., Poté, J., \& Wildi, W. (2009). Influence of Freshwater Sediment Characteristics on Persistence of Fecal Indicator Bacteria. Water, Air, and Soil Pollution, 203(14), 217-227. doi: 10.1007/s11270-009-0005-0

Kay, D., Stapleton, C. M., Wyer, M. D., McDonald, A. T., Crowther, J., Paul, N., . . Gardner, S. (2005). Decay of intestinal enterococci concentrations in high-energy estuarine and coastal waters: towards real-time T90 values for modelling faecal indicators in recreational waters. Water Res, 39(4), 655-667. doi: 10.1016/j.watres.2004.11.014

Khosravi, R., Shahryari, T., Halvani, A., Khodadadi, M., Ahrari, F., \& Mehrizi, E. A. (2013). Kinetic analysis of organic matter removal in stabilization pond in the wastewater treatment plant of Birjand. Advances in Environmental Biology, 7(6), 1182-1187.

Maïga, Y., Denyigba, K., Wethe, J., \& Ouattara, A. S. (2009). Sunlight inactivation of Escherichia coli in waste stabilization microcosms in a sahelian region (Ouagadougou, Burkina Faso). Journal of Photochemistry and Photobiology B: Biology, 94(2), 113-119.

McGuigan, K. G., Conroy, R. M., Mosler, H. J., du Preez, M., Ubomba-Jaswa, E., \& Fernandez-Ibanez, P. (2012). Solar water disinfection (SODIS): a review from bench-top to roof-top. J Hazard Mater, 235-236, 29-46. doi: 10.1016/j.jhazmat.2012.07.053

Misstear, D. B., Murtagh, J. P., \& Gill, L. W. (2013). The Effect of Dark Periods on the UV Photolytic and Photocatalytic Disinfection of Escherichia coli in a Continuous Flow Reactor. Journal of Solar Energy Engineering, 135(2), 021012-021012. doi: 10.1115/1.4023179

Ndounla, J., Kenfack, S., Wéthé, J., \& Pulgarin, C. (2014). Relevant impact of irradiance (vs. dose) and evolution of $\mathrm{pH}$ and mineral nitrogen compounds during natural water disinfection by photoFenton in a solar CPC reactor. Applied Catalysis B: Environmental, 148-149(0), 144-153. doi: http://dx.doi.org/10.1016/j.apcatb.2013.10.048

Noble, R. T., Lee, I. M., \& Schiff, K. C. (2004). Inactivation of indicator micro-organisms from various sources of faecal contamination in seawater and freshwater. J Appl Microbiol, 96(3), 464-472. doi: 10.1111/j.1365-2672.2004.02155.x

OECD Guidelines for Testing of Chemicals, Simulation Test-Aerobic Sewage Treatment 303A, 2001

Oguma, K., Katayama, H., \& Ohgaki, S. (2002). Photoreactivation of Escherichia coli after low-or medium-pressure UV disinfection determined by an endonuclease sensitive site assay. Applied and environmental microbiology, 68(12), 6029-6035.

Quek, P. H., \& Hu, J. (2008). Indicators for photoreactivation and dark repair studies following ultraviolet disinfection. Journal of industrial microbiology \& biotechnology, 35(6), 533-541.

Rincón, A.-G., \& Pulgarin, C. (2004a). Field solar E. coli inactivation in the absence and presence of TiO2: is UV solar dose an appropriate parameter for standardization of water solar disinfection? Solar Energy, 77(5), 635-648. doi: 10.1016/j.solener.2004.08.002

Rincón, A.-G., \& Pulgarin, C. (2007). $\mathrm{Fe}^{3+}$ and $\mathrm{TiO}_{2}$ solar-light-assisted inactivation of $E$. coli at field scale: Implications in solar disinfection at low temperature of large quantities of water. Catalysis Today, 122(1), 128-136.

Sichel, C., Tello, J., de Cara, M., \& Fernández-Ibáñez, P. (2007). Effect of UV solar intensity and dose on the photocatalytic disinfection of bacteria and fungi. Catalysis Today, 129(1-2), 152-160. doi: 10.1016/j.cattod.2007.06.061

Troussellier, M., Bonnefont, J.-L., Courties, C., Derrien, A., Dupray, E., Gauthier, M., . . . Martin, Y. (1998). Responses of enteric bacteria to environmental stresses in seawater. Oceanologica Acta, 21(6), 965-981. 
Ubomba-Jaswa, E., Navntoft, C., Polo-Lopez, M. I., Fernandez-Ibanez, P., \& McGuigan, K. G. (2009). Solar disinfection of drinking water (SODIS): an investigation of the effect of UV-A dose on inactivation efficiency. Photochem Photobiol Sci, 8(5), 587-595. doi: 10.1039/b816593a

Vidovic, S., Mangalappalli-Illathu, A. K., Xiong, H., \& Korber, D. R. (2012). Heat acclimation and the role of RpoS in prolonged heat shock of Escherichia coli O157. Food Microbiology, 30(2), 457464.

Von Sperling, M. (2005). Modelling of coliform removal in 186 facultative and maturation ponds around the world. Water Res, 39(20), 5261-5273.

White, G. C. (2010). White's handbook of chlorination and alternative disinfectants: Wiley.

Xu, P., Brissaud, F., \& Fazio, A. (2002). Non-steady-state modelling of faecal coliform removal in deep tertiary lagoons. Water Res, 36(12), 3074-3082.

Yamahara, K. M., Layton, B. A., Santoro, A. E., \& Boehm, A. B. (2007). Beach Sands along the California Coast Are Diffuse Sources of Fecal Bacteria to Coastal Waters. Environmental Science \& Technology, 41(13), 4515-4521. doi: 10.1021/es062822n 


\section{List of Figures}

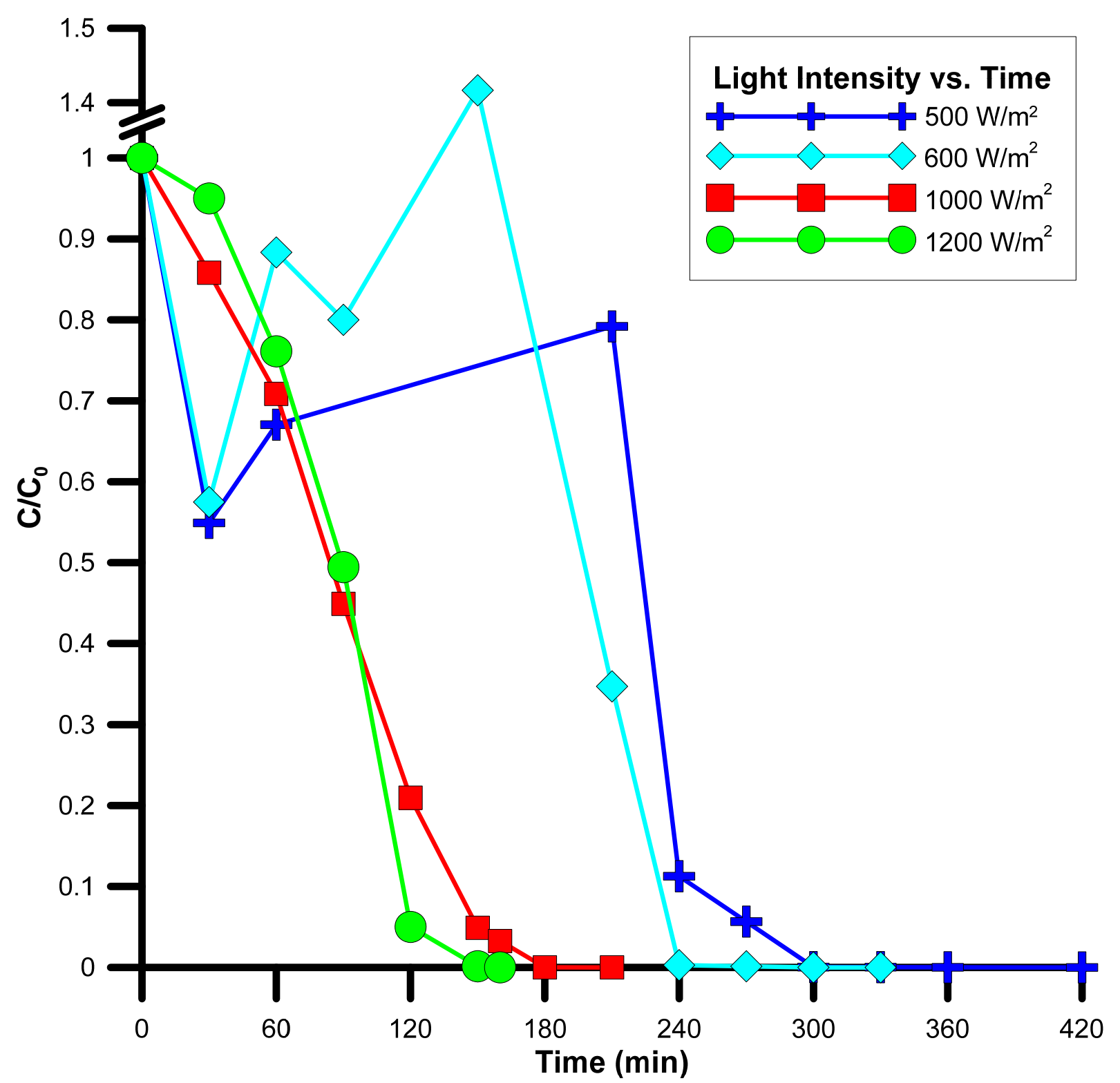

Figure 1 - Effect of various light intensities in bacterial inactivation and the subsequent survival in the dark. Inactivation kinetics summary. 


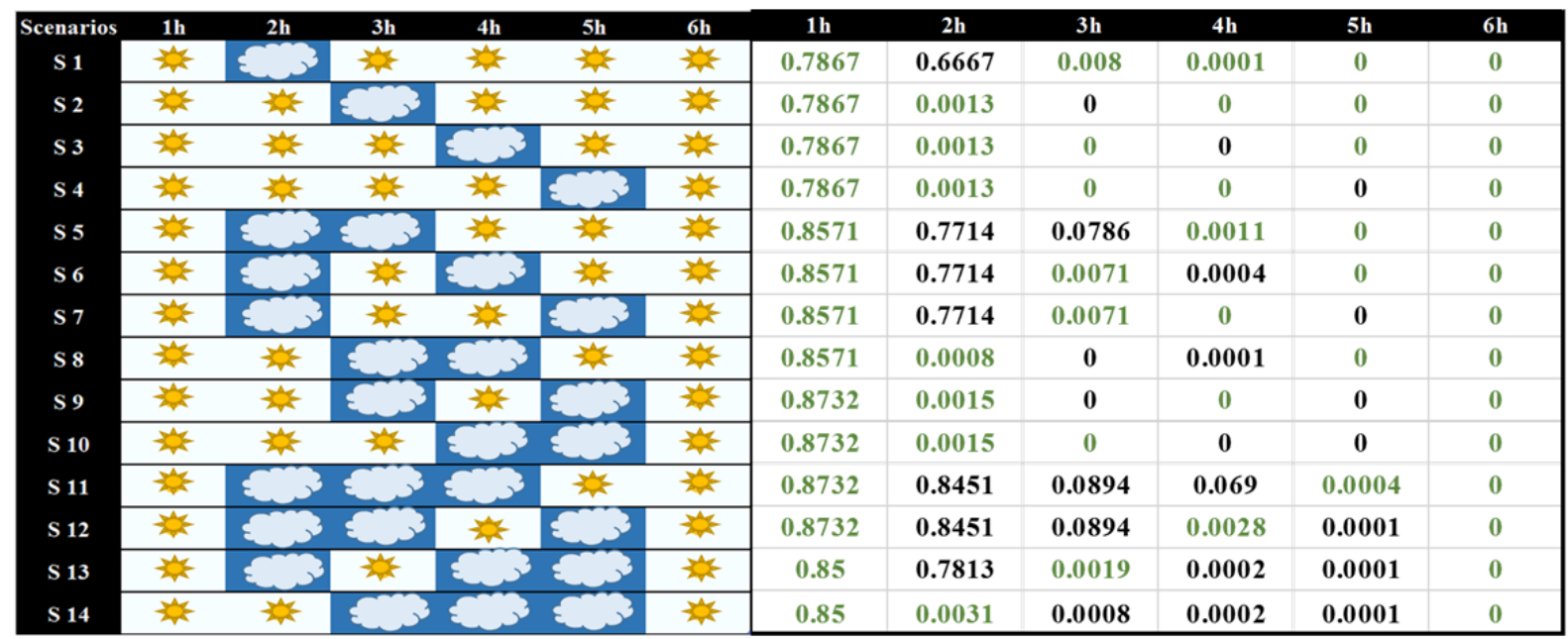

a)

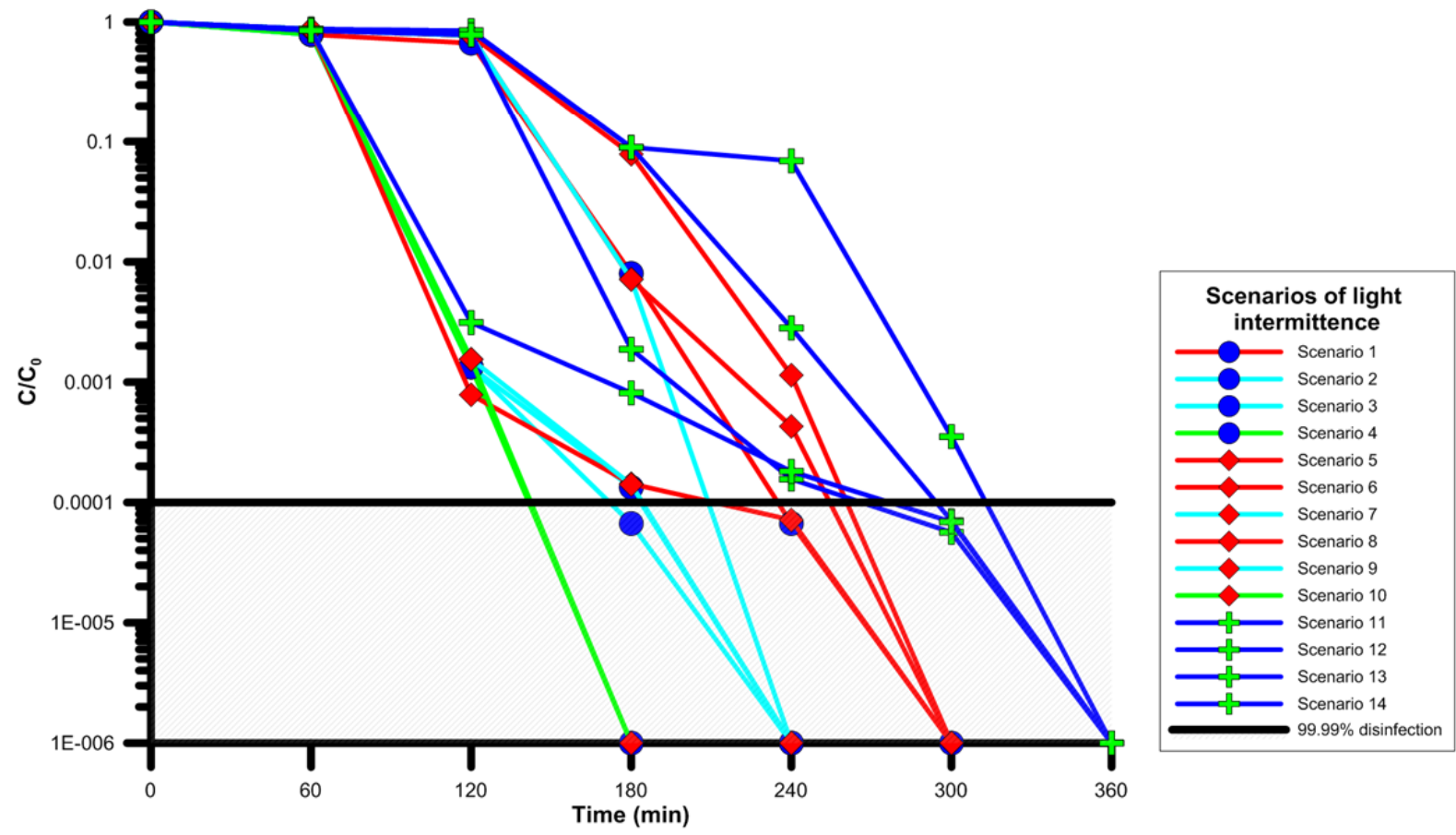

b)

Figure 2 - Effects of light intermittence on bacterial inactivation. (a) Summary of the 14 light scenarios tested in the experimental design. (b) Inactivation kinetics grouped per intermittence length and total exposure time. 

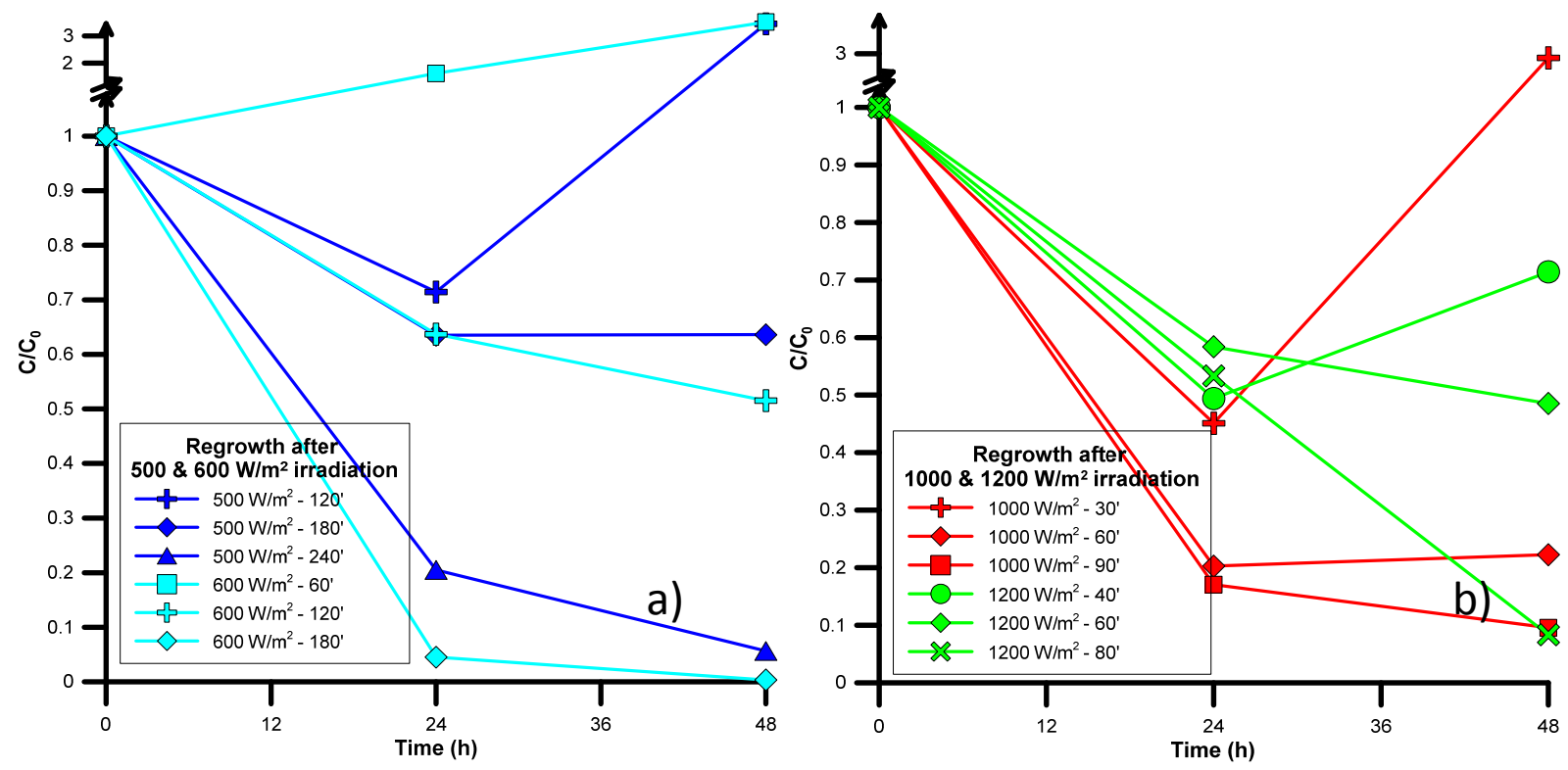

Figure 3 - Irradiance and long term survival in the dark. (a) Bacterial kinetics after irradiation with low intensity light. (a) Bacterial kinetics after irradiation with high intensity light. 


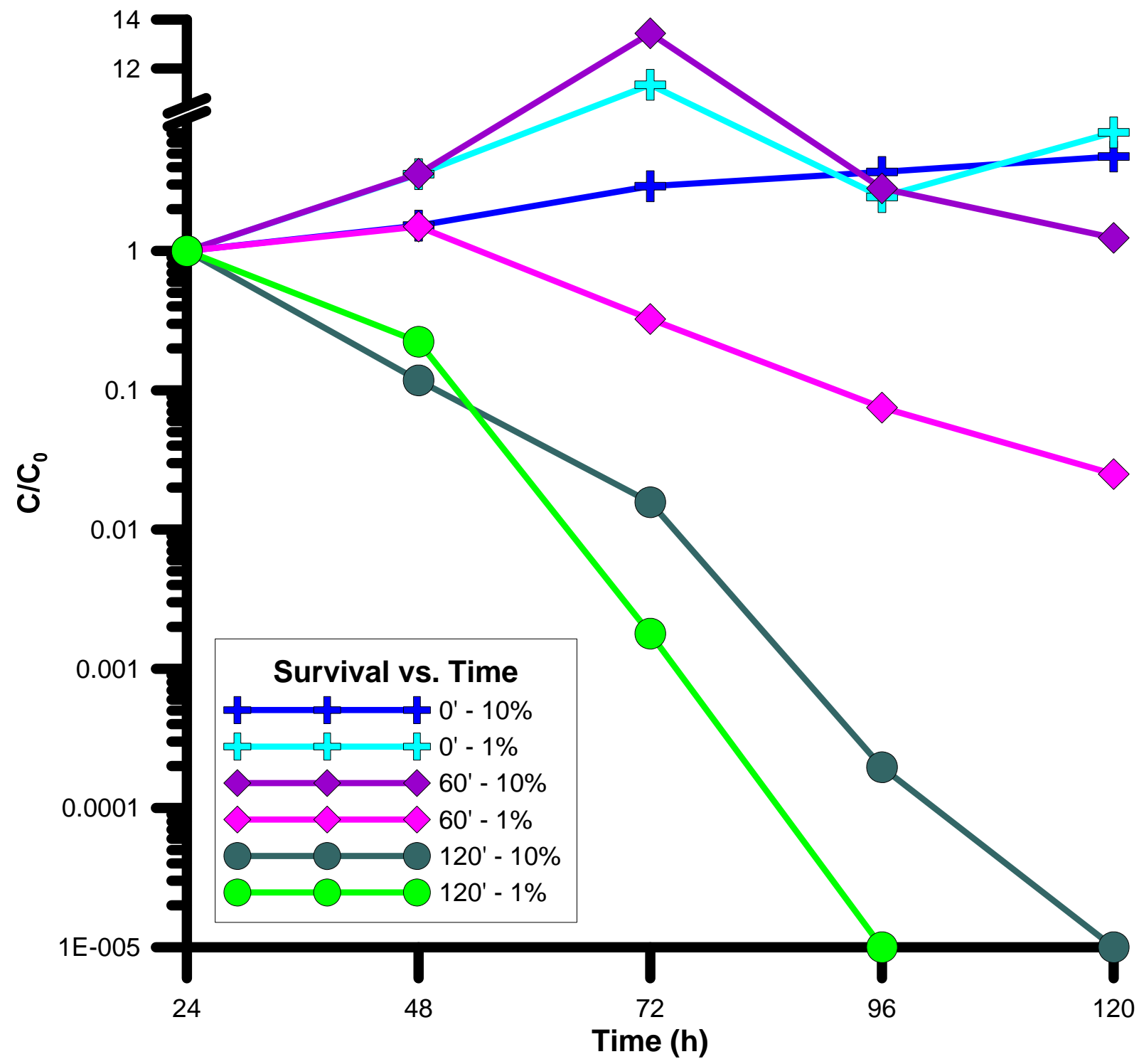

Figure 4 - Survival kinetics of previously irradiated bacteria in Lake Leman water. Results are presented per pre-illumination times and post-irradiation dilution ratio. 